\title{
The Adoption of Open Educational Resources by One Community College Math Department
}
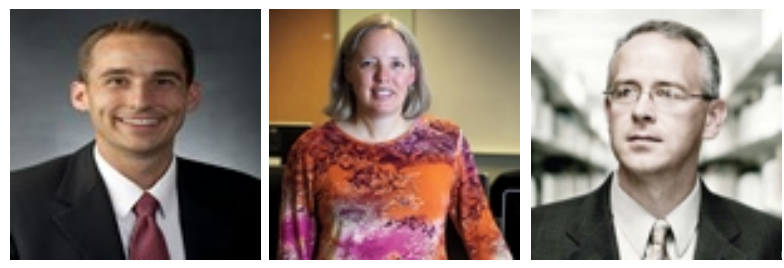

John Levi Hilton III', Donna Gaudet ${ }^{2}$, Phil Clark² (not shown), Jared Robinson ${ }^{1}$ (not shown), and David Wiley 1

1Brigham Young University, USA, ${ }^{2}$ Scottsdale Community College

\section{Abstract}

The high cost of textbooks is of concern not only to college students but also to society as a whole. Open textbooks promise the same educational benefits as traditional textbooks; however, their efficacy remains largely untested. We report on one community college's adoption of a collection of open resources across five different mathematics classes. During the 2012 fall semester, 2,043 students in five different courses used these open access resources. We present a comparison between the previous two years in terms of the number of students who withdrew from the courses and the number that completed the courses with a $\mathrm{C}$ grade or better. Our analysis suggests that while there was likely no change in these educational outcomes, students who have access to open access materials collectively saved a significant amount of money. Students and faculty were surveyed as to their perceptions of these materials and the results were generally favorable.

Keywords: Open educational resources; open textbooks; electronic textbooks; open access; sustainability; mathematics education 


\section{Introduction}

Wiley and Green (2012) state that "College students spend an average of $\$ 900$ per year on textbooks-26 percent of the cost of tuition at a public, four-year university" (p. 83). This percentage is sometimes even higher at community colleges where tuition and fees are traditionally lower than at universities. Paying for expensive textbooks seems particularly questionable in introductory courses, in which the information being presented is largely stable and the knowledge is readily available. Textbooks are only part of a larger issue, namely that many students struggle to pay for higher education in general and textbooks specifically (Allen, 2011). According to Perry (2012),

The $812 \%$ increase in the price of college textbooks since 1978 makes the run-up in house prices and housing bubble (and subsequent crash) in the 2000s seem rather inconsequential, and the nine-fold increase in textbook prices also dwarfs the increase in the cost of medical services over the last three decades. Compared to the $250 \%$ increase in the Consumer Price Index (CPI) over the last 34 years, college textbooks have risen more than three times the amount of the average increase for all goods and services.

Martin and Lehren (2012) report that in the United States alone, outstanding student loans (part of which funds are used for purchasing textbooks) now total over one trillion dollars. Although textbooks are not the exclusive reason for this debt, Buczynski (2007) argues that particularly for community college students, textbook prices can be a significant part of their overall college expenses.

Hilton and Wiley (2011) suggest that using open textbooks can provide substantial cost savings to students without compromising educational efficacy. Open textbooks are similar to traditional textbooks in terms of content; however, they are generally available for free in digital format, along with low-cost print copies. Such textbooks are classified as being a subset of open educational resources (OER). OER have the advantage of being freely available online and have Creative Commons licenses that (among other things) allow for them to be reused for free in a variety of contexts (Bissell, 2009; D’Antoni, 2009; Downes, 2007). Bliss (2013) writes that

numerous projects have been undertaken to develop OER, including the creation of OpenCourseWare at MIT and several other universities (see http:// www.ocwconsortium.org), education modules like those available by Connexions (see http://cnx.org), openly available textbooks such as those offered by CK12 or the Saylor Foundation (see http://ck12.org; http:// www.saylor.org), openly available classes (Fini, et 
al., 2008), and [some versions of] Massively Open Online Courses (MOOC) (Mackness, et al., 2010; Fini, 2009).

While little research has been done regarding student perceptions of OER, Lindshield and Adhikari (2013) report that students enjoy using open textbooks.

Because this is a relatively recent phenomenon, little research has been undertaken to assess how utilizing OER impacts student learning. Hilton and Laman (2012) reported on Houston Community College's adoption of an open textbook for a psychology class. During the fall semester of 2011, 690 students used this open textbook. They stated that "Compared with students using a traditional text in the spring of 2011, students who used the free online textbook scored higher on departmental final examinations, had higher grade point averages in the class and had higher retention rates" (p. 265). In the context of a university, Feldstein et al. (2012) found that students in business courses that utilized OER were more likely to use the learning materials, and found that these courses appeared to have lower withdrawal rates and higher grades than those in classes without open materials. Similarly, Wiley et al. (2012) found that a high school district in Utah, USA that used open textbooks for its science curriculum saw essentially no change in their state standardized test scores. In the present study, we add to the body of knowledge surrounding the impact of using open educational resources in a community college setting by reporting on Scottsdale Community College's adoption of open course materials across five different math courses.

\section{Context of the Study}

This study took place at Scottsdale Community College (SCC), a community college in Arizona, USA with approximately 10,000 students. Males comprise $54 \%$ of its student body, and $46 \%$ are female; $76 \%$ of its students are Caucasian, $11 \%$ Hispanic, 5\% Native American, 4\% African American, and 4\% Asian/ Pacific Islander. Like many who attend college in the United States, some students at SCC have difficulty paying for the cost of education. Our survey of 966 mathematics students determined that slightly less than half of these students (451) used some combination of loans, grants, and tuition waivers to pay for the cost of their education. The difficulties of paying for college may prevent some students from purchasing textbooks, potentially limiting their educational growth, potentially limiting their access to information and knowledge.

The mathematics faculty at SCC viewed the shift to open materials as one that could provide greater access to learning resources at a lower price, without compromising student learning. The decision to adopt open materials evolved over a period of several years with different instructors in the Mathematics department taking different approaches. In the spring of 2012, department members collectively created a cohesive strategy for using open educational resources. Previously open materials had been used in only a few classes. However, in the fall of 2012 OER was employed throughout five different courses at SCC. That semester, all of the materials requested by the five 
different math courses were available online for free; in some cases, hard copies of textbooks were made available for optional purchase at prices ranging from $\$ 13.00$ to $\$ 30.00$. We next list the courses that utilized open materials and describe the open materials that were employed.

\section{Introductory Algebra Math 09x.}

Three primary OER were employed in this class. First there was a student workbook, written by SCC faculty members. Because many of the instructors at SCC do hands-on work with groups and white-board work in class, they wanted materials that would support this approach. They created a workbook that contains examples (which students complete by watching videos), practice problems, and end-of-lesson assessments. The SCC faculty published this workbook using a Creative Commons license. Second, they used the Internet Mathematics Assessment System, "a web-based math assessment tool for delivery and automatic grading of math homework and tests" (Lippman, n.d.). This open source software is licensed under the GNU Public License. Finally an OER textbook, CK12 Introductory Algebra (Gloag, Gloag, and Kramer), was used primarily as an online resource; few instructors required the book, relying instead on the video modules that were part of the workbooks.

\section{Intermediate Algebra Math 12x.}

Materials similar to those used in Math 09x (albeit at a higher level) were available for Math 12x. The textbook in this class was CK12 Intermediate Algebra (Gloag, Gloag, Kramer, and Landers).

\section{College Algebra Math 15x.}

As with the Math 09x and Math 12x courses, Math 15x utilized a student workbook created by SCC faculty members using a Creative Commons license and the Internet Mathematics Assessment System. It also used online lessons created in Softchalk (www.softchalk.com) that introduces the material to students. These lessons include text, videos, applets, images, and comprehension questions that the students answer and get a score at the end. Unlike the other resources they employed, Softchalk is not open source. Finally, a combination of two textbooks, Precalculus by Lippman and Rasmuessan and Precalculus by Stitz and Zeager, was used. SCC took advantage of the remixability of OER to combine these two open textbooks into one in order to ensure that the final version covered all of the competencies required by Maricopa Community Colleges, of which SCC is one. This type of remix is more fully described by Hilton, Wiley, Stein, and J ohnson (2010). In addition, we note that SCC took advantage of the CC-license to make small textbook revisions in order to ensure that the content matched the local requirements. 


\section{Trigonometry MAT182.}

This course utilized a portion of the book Precalculus by Lippman and Rasmuessan, along with the Internet Mathematics Assessment System.

\section{PreCalculus MAT187.}

The resources utilized in this class were similar to those employed in MAT15x. SCC's precalculus course is a combination of college algebra and trigonometry; the college algebra portion is the same as what is taught in Math 150. However, Softchalk lessons were not used in this course.

\section{Research Questions and Method}

In this study we had three key research questions.

1. How much money did students save because of the use of open textbooks?

2. Did the patterns of retention and student success change after OER was implemented?

3. How did students and faculty perceive OER quality, compared to other materials?

In the fall of 2012, 2,043 students taking 65 sections of math classes used the open materials. Forty-two different instructors were involved; 643 students were enrolled in MAT09x, 764 in MAT12x, 461 in MAT15x, 95 students in MAT182, and 80 students in MAT187. Ninety-three of these students were enrolled in distance versions of the respective courses. In order to investigate whether these materials influenced (positively or negatively) student learning outcomes we examined institutional data reported by SCC on withdrawal rates and those completing the course with a $\mathrm{C}$ grade or better. These data are publicly available. We also surveyed both students and faculty as to their experiences with the open materials. These surveys were based on the work done by Bliss, et. al (2013), and were administered during class; 966 students completed the survey (this number excludes a small number [approximately 3\%] of surveys that were discarded because the students evidently randomly bubbled in responses as evidenced by their out-of-bounds responses). 


\section{Results}

\section{Textbook Costs}

SCC faculty members who were surveyed as to the costs of the textbooks they typically have required in the past reported that the average cost of these textbooks was $\$ 125$. Some courses ranged as high as $\$ 220$. As stated above all of the materials necessary for the five different math courses included in this study were available online for free; in some instances hard copies of textbooks were also made available for optional purchase at prices ranging from $\$ 13.00$ to $\$ 30.00$. If we assume that all 2,043 students would have purchased a \$125.00 textbook, and instead used the openly licensed, free online materials, the resulting savings would be $\$ 255,375.00$. Clearly not every student would have purchased a new textbook, and some students may have opted to purchase a printed copy of the open materials, but this figure does indicate the significant cost savings to students that can result from a single semester's adoption of OER.

\section{Grades and Completion Rates}

Our second research question asked if there were any changes in student success patterns or completion rates in the fall of 2012, the semester in which open educational resources were used. Student success patterns were measured by the rate at which students passed the math class with a $\mathrm{C}$ grade or better. The results for the fall semesters during years 2010 to 2012 are shown in Table 1 (we only compared fall numbers given that the student population in the courses shifts substantially between fall and spring semesters).

Table 1

Aggregated Data Fall 2010 - Fall 2012: Overall Grades

\begin{tabular}{|l|l|l|l|}
\hline $\begin{array}{l}\text { Percentage of students earning } \\
\text { a C grade or better }\end{array}$ & Fall 2010 & Fall 2011 & Fall 2012 \\
\hline MAT 09x & $62 \%(790)$ & $67 \%(704)$ & $51 \%(643)$ \\
\hline MAT 12x & $60 \%(748)$ & $63 \%(721)$ & $62 \%(764)$ \\
\hline MAT 15x & $65 \%(448)$ & $64 \%(388)$ & $65 \%(461)$ \\
\hline MAT 182 & $56 \%(106)$ & $61 \%(109)$ & $58 \%(95)$ \\
\hline MAT 187 & $53 \%(72)$ & $48 \%(82)$ & $55 \%(80)$ \\
\hline
\end{tabular}

In order to examine whether the distribution of student success differed significantly from 2011 to 2012, we conducted a z-test for comparing proportions for each course. The results of these z-tests revealed no significant change in student success rates from 2011 to 2012, with one notable exception: The percentage of student success in Math 09X declined significantly to 51\% in 2012 compared to percentages of $67 \%$ and $62 \%$ in 
the prior two years. This result was significant at the $\alpha=.05$ level, $z=-5.97, p<.001$. Possible reasons for this change are included in the discussion section. Otherwise, it does not appear that student success rates significantly varied from the same rate in 2011.

A similar pattern was observed when examining the data for course completion rates in 2012 compared to previous years. The 2012 completion rate in Math 09X was significantly lower than the completion rate in the previous year, $z=-6.11, p<.001$. Again, possible explanations for this change will be subsequently discussed. There did not appear to be a drop in completion rate in other courses in the year that OER were adopted. Table 2 summarizes completion rates for the classes that were the focus of this study.

Table 2

Aggregated Data Fall 2010 - Fall 2012: Completion Rates

\begin{tabular}{|l|l|l|l|}
\hline Completion rates & Fall 2010 & Fall 2011 & Fall 2012 \\
\hline MAT 09x & $75 \%(790)$ & $79 \%(704)$ & $64 \%(643)$ \\
\hline MAT 12x & $79 \%(748)$ & $76 \%(721)$ & $75 \%(764)$ \\
\hline MAT 15x & $73 \%(448)$ & $72 \%(388)$ & $76 \%(461)$ \\
\hline MAT 182 & $58 \%(106)$ & $72 \%(109)$ & $72 \%(95)$ \\
\hline MAT 187 & $68 \%(72)$ & $62 \%(82)$ & $64 \%(80)$ \\
\hline
\end{tabular}

\section{Student Perceptions of the Materials}

Our third research question asked how students and faculty at SCC perceived the quality and content of the new OER. We surveyed students to learn of their perceptions of the OER used in their classes. Students were generally positive about the materials. In total, 83\% either strongly agreed or slightly agreed with the statement, "Overall, the materials adequately supported the work I did in class." Figure 1 more specifically illustrates their responses to this statement. 


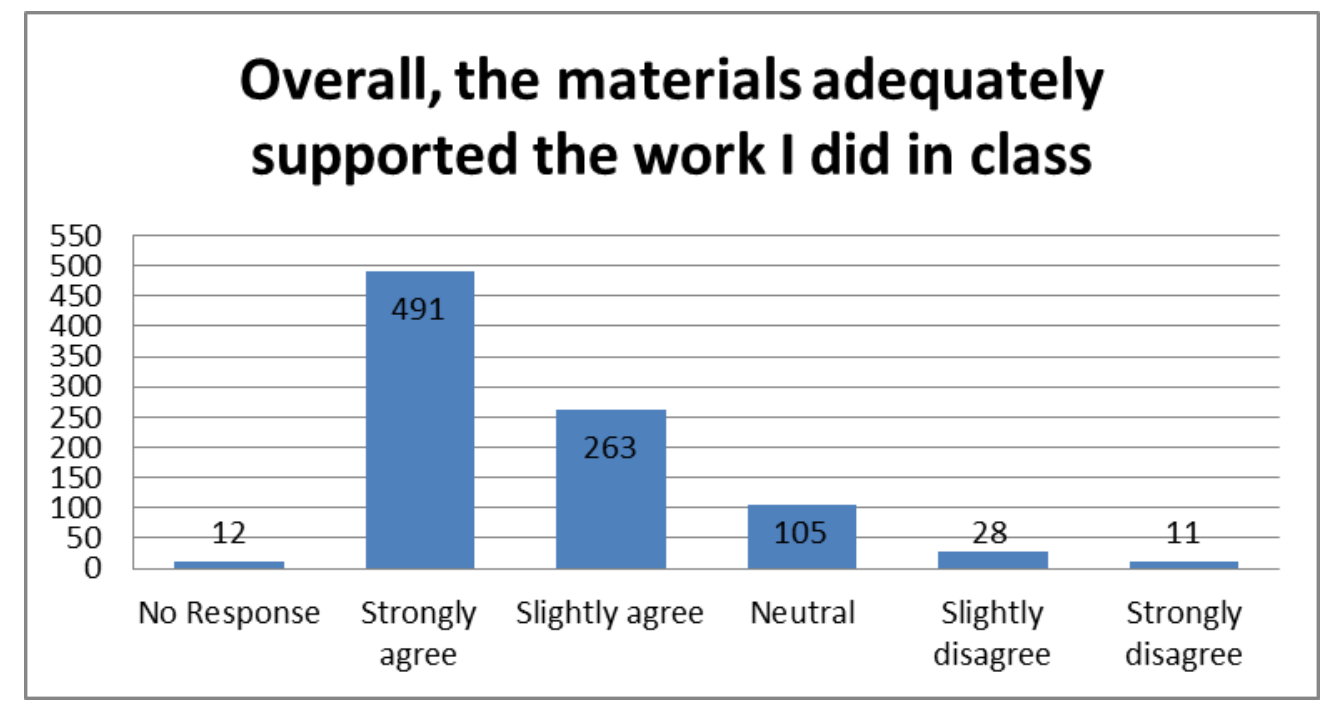

Figure 1. Student responses to the statement, "Overall, the materials adequately supported the work I did in class.”

Similarly, students tended to agree with the statement, "Overall, the materials adequately supported the work I did outside of class," as outlined in Figure 2.

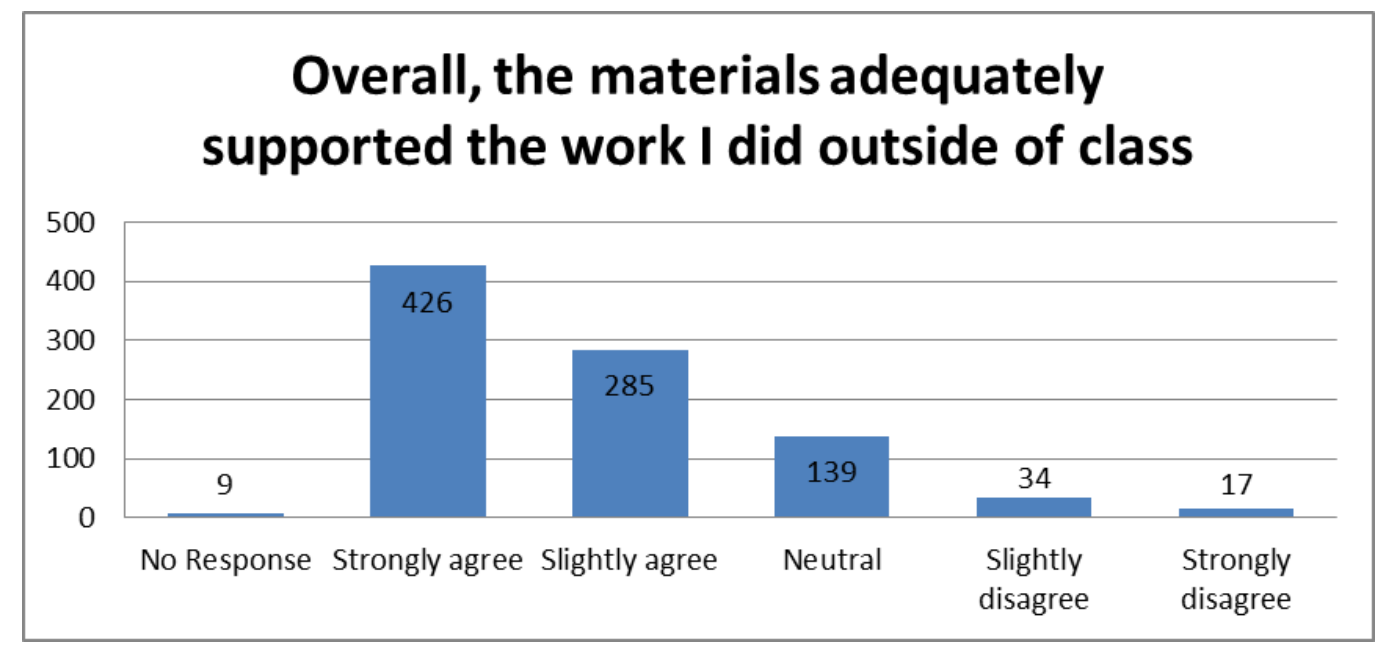

Figure 2. Student responses to the statement, "Overall, the materials adequately supported the work I did outside of class.”

Students also provided an overall endorsement of the open materials as evidenced by Figure 3. 


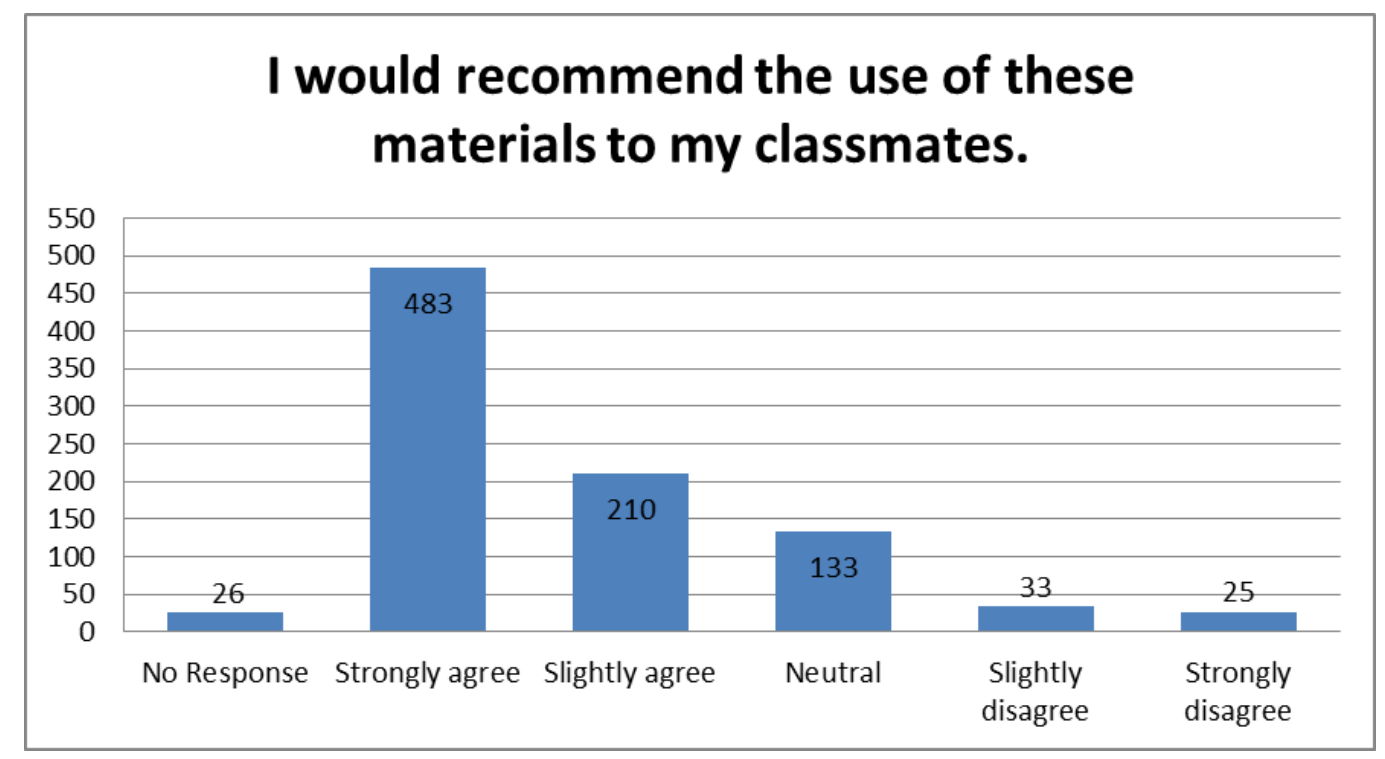

Figure 3. Student responses to the statement, "I would recommend the use of these materials to my classmates.”

The student survey also included free-response questions. Their answers to these questions were again generally positive. For example, of the 255 responses to the question, "What additional comments do you have regarding the quality of the open materials used in your class?" 210 (82\%) were positive. Representative comments include the following statements: "Great!" "They were good. Definitely worth not having a massed produced book for." "I never had an open materials class before. It made work less stressful and learning more enjoyable - didn't constantly feel frustrated and was able to look through notes when I got stuck." "The quality was excellent. It really helped my understanding."

Several of the answers to this question focused on the price of the materials such as the following: "Keep them, buying textbooks is out of date and I think materials should be inexpensive." "I love saving money, I am poor." "I like the open materials, textbooks are so expensive that it makes me not want to buy them."

Of the student comments not coded as positive, representative statements included the following: "That was fine but you need better material," or "Fine. I used Youtube a lot to get help and other math websites."

\section{Faculty Perceptions of the Materials}

Twenty faculty members at SCC completed our survey (response rate of 48\%) regarding their opinions on the OER that they had employed. In general they viewed the open materials positively. In response to the question, "How would you rate the quality of the OER textbook used for this course?" three instructors rated the book as "WORSE than 
the quality of texts in my other courses"; nine instructors said they were "About the SAME AS the quality of texts in my other courses"; and six reported that they were "BETTER than the quality of texts in my other courses" (two faculty members left this question blank).

Of the 15 instructors who responded to the question, "Do you feel that the OER materials adequately supported the work that was completed INSIDE the classroom? Why or why not?" 13 answered "yes," and then provided an explanatory comment. The following are two examples of these answers: "Yes, although I will rearrange some of the material next time around. For example, I like to cover properties of exponents BEFORE exponential and logarithmic functions as we use these properties at that time in my class" and "Yes, it is a complete resource." The two responses that did not begin with a "yes" are as follows: "Need more specific examples" and "Most of the time it was supported."

Similarly, of the 15 instructors who responded to the question, "Do you feel that the OER materials adequately supported the work that was completed OUTSIDE the classroom? Why or why not?" 13 answered "yes." Sample responses are "Yes. These materials provided the students useful resources" and "Yes. It focused in the lesson well." The remaining two responses were "Mostly - often students had online questions, which were discussed through MathAS or in class" and "In Math 12x, the online HW contained questions that were not written in the style of the workbook questions. Some students had difficulty in transferring their skills to the online questions."

\section{Discussion and Limitations}

Our first research question pertained to the amount of money students saved as a result of the open textbooks. As we reported above, if all 2,043 students would have purchased a \$125.00 textbook, and instead used the openly licensed, free online materials, the total savings would have been $\$ 255,375.00$. Because we did not directly measure the amount of money students spent purchasing textbooks during the years 2010-2012, we cannot ultimately determine what the exact cost savings were. However, even if only half the students would have purchased the traditional textbooks, the savings experienced by the students at one community college in one semester would still have eclipsed $\$ 100,000.00$.

To answer our second research question, we examined the rates of student success and course completion in the year of OER adoption compared to the previous two years. Although this case study prohibits any causal attribution to observed change or lack of change in this data, the patterns might provide rationale and direction for future research. 
With the exception of Math 09x, there were no changes observed in either rates of success or completion. While there was an observed negative change in both student success and completion rates for the Math 09x course, there were external factors that suggest that this change may not have been due to the adoption of a new curriculum. Immediately prior to the fall 2012 semester, SCC changed the placement system they were using to determine which math courses students would take. As a result, students who in previous years would have been placed into a lower math course based on their placement test scores were instead put into Math 09x. In this case, this policy change is perfectly confounded with the adoption of open materials. Given the similarity in the process and content of the materials in Math 09x to other courses, and the absence of a similar pattern of change in those other courses, there is likely reason to doubt that the change in student success and completion for that course is attributable to OER adoption. Future studies and evaluation cycles at SCC might seek to further explore whether the OER in Math 09x functions differently than the OER in other courses and to what extent this policy change at SCC impacts student success and completion in Math 09x.

The patterns of student and faculty responses to the open texts used reveal largely favorable receptions to the open resources. Students were not specifically asked to compare their experience with the open texts with other traditional curricular materials they had used, but their responses indicated an overall level of satisfaction with the OER. Perhaps not surprisingly, in open responses, students focused on the cost of the books rather than the quality of the books in comparative statements.

Faculty, on the other hand, were asked to make comparisons between the quality of the open and traditional materials. While responses tended to favor open materials in terms of overall quality, there was disagreement among the instructors. This is perhaps not surprising considering historic diversities of preference of faculty with regard to textbooks and a wide range of other learning materials. But one interesting thread coming from teacher open responses was a sense that teachers were aware that flaws in open textbooks could be readily fixed. For example, in response to the question, "Do you feel that the OER materials adequately supported the work that was completed OUTSIDE the classroom? Why or why not" one teacher answered, "Yes, although I will rearrange some of the material next time around. For example, I like to cover properties of exponents BEFORE exponential and logarithmic functions as we use these properties at that time in my class." Otherwise, teachers responded mostly positively about the utility of texts in promoting student learning both inside and outside of class.

It seems worth noting that the ability to ask these kinds of questions to teachers and students highlights a unique opportunity for evaluation of open educational resources. Because any materials used or produced are readily revised, remixed, reused, and redistributed at the campus level, student and faculty perceptions can be easily leveraged to provide real, meaningful improvement of materials for subsequent iterations of the course. The same questions asked of traditional textbooks, in contrast, 
would by necessity be purely academic, since copyright restrictions would prohibit faculty from making substantive changes to those materials.

Ultimately, we believe that our key findings are that (1) there was not a strong correlation between using an open textbook and changes in student learning and (2) students whose faculty assign open textbooks potentially save a significant amount of money. OER can be used to drastically improve the affordability of education while adhering to the medical ethics maxim primum non nocere, "first, do no harm".

\section{Conclusion}

This study may represent an important step in examining how the use of open materials may influence both the cost of post-secondary education and student learning. While we can be certain that students and faculty members viewed these particular materials positively, it is not clear whether they had any impact on student learning. Additional research is needed to answer important questions in this area of study. For example, a future study could determine whether or not the use of open resources has a statistically significant effect on students obtaining and using resources for a course. It is possible that many students do not get the required and recommended materials for a course due to the cost of the materials. Does having all materials for courses freely online increase student access to these learning materials? Moreover, does increased access to materials lead to increased learning? Do students in distance education perceive OER differently from those in a face-to-face setting? Continued work in multiple contexts is needed to gain a more detailed view of what happens when OER are substituted for traditional learning materials.

Notice of full disclosure: Some of the authors of this study were involved in the adoption and modification of open materials discussed in this article.

This study was funded in part with a grant from the Bill and Melinda Gates Foundation.

\section{OER Materials Discussed in the Article}

The OER materials discussed in this paper can be found at http://sccmath.wordpress.com. Click the tabs at top to 09x, 12x. This will give links to the workbook and all videos. For links to the workbooks and textbooks for all classes, go to https:// score.scottsdalecc.edu/?q=s13

For college algebra https:// score.scottsdalecc.edu/ ?q=nodequeue/ 14

The Internet Mathematics Assessment System is available at http:// www.imathas.com/. 


\section{References}

Allen, N. (2011). High prices prevent college students from buying assigned textbooks [Press release]. Retrieved from http:// www.studentpirgs.org/ news/ap/ highprices-prevent-college-students-buying-assigned-textbooks.

Bissell, A. (2009). Permission granted: Open licensing for educational resources. Open Learning, The J ournal of Open and Distance Learning, 24, 97-106.

Bliss, T. J ., Hilton, J ., Wiley, D., \& Thanos, K. (2013). The cost and quality of open textbooks: Perceptions of community college faculty and students. First Monday, 18(1).

Bliss, T. J ., Robinson, J ., Hilton, J ., \&Wiley, D. (2013). An OER COUP: College teacher and student perceptions of open educational resources. The J ournal of Interactive Media and Education, 12(1).

Buczynski,J . (2007). Faculty begin to replace textbooks with "freely" accessible online resources. Internet Reference Services Quarterly, 11(4), 169-179. Retrieved from http:// dx.doi.org/ 10.1300/J 136v11n04_ 11

D’Antoni, S. (2009). Open educational resources: Reviewing initiatives and issues. Open Learning, The J ournal of Open and Distance Learning, 24, 3-10.

Downes, S. (2007). Models for sustainable open educational resources. Interdisciplinary J ournal of Knowledge and Learning Objects, 3, 29-44.

Hilton, J ., Wiley, D., Stein, J ., \&J ohnson, A. (2010). The four R's of openness and ALMS Analysis: Frameworks for open educational resources. Open Learning: The J ournal of Open and Distance Learning, 25(1), 37- 44.

Hilton, J ., \& Wiley, D. (2011). Open-access textbooks and financial sustainability: A case study on Flat World Knowledge. The International Review of Research in Open and Distance Learning, 12(5). Retrieved from http:// www.irrodl.org/index.php/irrodl/article/view/ 960/ 1860

Hilton, J ., \& Laman, C. (2012). One college’s use of an open psychology textbook. Open Learning, 27(3), 265-272.

Lippman, D. (n.d.). http:// www.imathas.com/

Lindshield, B., \&Adhikari, K. (2013). Online and campus college students like using an open educational resource instead of a traditional textbook. J ournal of Online Teaching and Learning, 29(1). Retrieved from http://jolt.merlot.org/vol9no1/lindshield_0313.htm. 
Martin, A., \&Lehren, A. W. (2012). A generation hobbled by the soaring cost of college. The New York Times. Retrieved from http:// www.nytimes.com/2012/05/ 13/ business/ student-loans-weighing-downa-generation-with-heavy-debt.html? $r=3 \&$ ref=business.

Perry, M. (2012). The college textbook bubble and how the "open educational resources" movement is going up against the textbook cartel. American Enterprise Institute. Retrieved from http:// www.aei-ideas.org/ 2012/12/ the-collegetextbook-bubble-and-how-the-open-educational-resources-movement-is-goingup-against-the-textbook-cartel/.

Wiley, D., Hilton, J ., Ellington, S., \& Hall, T. (2012). A preliminary examination of the cost savings and learning impacts of using open textbooks in high school science classes. International Review of Research in Open and Distance Learning.

Wiley, D., \& Green, C. (2012). Why openness in education? In D. G. Oblinger (Ed.), Game changers: Education and information technologies. Educause.

\section{Athabasca University $\mathbf{Z}$}

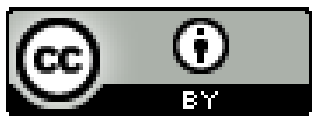

